\title{
Demographic predictors of hospitalization and mortality in US children with COVID-19
}

\author{
Alvaro Moreira $^{1}$ (D) $\cdot$ Kevin Chorath ${ }^{2} \cdot$ Karthik Rajasekaran $^{2} \cdot$ Fiona Burmeister $^{1} \cdot$ Mubbasheer Ahmed $^{3} \cdot$ Axel Moreira $^{3}$ \\ Received: 17 October 2020 / Revised: 11 January 2021 / Accepted: 15 January 2021 / Published online: 20 January 2021 \\ (C) The Author(s), under exclusive licence to Springer-Verlag GmbH, DE part of Springer Nature 2021
}

\begin{abstract}
Understanding which children are at increased risk for poor outcome with COVID-19 is critical. In this study, we link pediatric population-based data from the US Center for Disease Control and Prevention to COVID-19 hospitalization and in-hospital death. In 27,045 US children with confirmed COVID-19, we demonstrate that African American [OR 2.28 (95\% CI: 1.93, 2.70)] or mixed race [OR 2.95 (95\% CI: 2.28, 3.82)] and an underlying medical condition [OR 3.55 (95\% CI: 3.14, 4.01)] are strong predictors for hospitalization. Death occurred in $39(0.19 \%)$ of 20,096 hospitalized children; children with a prior medical condition had an increased odd for death [OR 8.8 (95\% CI: 3.7, 21.1)].

Conclusion: Hospitalization and in-hospital death are rare in children diagnosed with COVID-19. However, children at higher risk for these outcomes include those with an underlying medical condition, as well as those of African American descent.
\end{abstract}

What is Known:

- Demographic factors are independent prognosticators of poor outcome in children with COVID-19.

What is New:

- Children with an underlying medical condition and those from an African American or mixed racelethnicity are at high risk for COVID-19 hospitalization.

- History of a comorbidity supersedes age, gender, and racelethnicity as a risk factor for in-hospital pediatric COVID-19 death.

Keywords COVID-19 · SARS-CoV-2 · Pediatric $\cdot$ Children · COVID-NET

Communicated by Nicole Ritz

Alvaro Moreira

MoreiraA@uthscsa.edu

Kevin Chorath

Kevin.Chorath@Pennmedicine.upenn.edu

Karthik Rajasekaran

Karthik.Rajasekaran@Pennmedicine.upenn.edu

Fiona Burmeister

Burmeisteri.fiona@gmail.com

Mubbasheer Ahmed

mxahmed1@texaschildrens.org

Axel Moreira

Axel.Moreira@bcm.edu

1 Department of Pediatrics, University of Texas Health San Antonio, 7702 Floyd Curl Drive, San Antonio, TX 78229, USA

2 University of Pennsylvania, Philadelphia, PA, USA

3 Baylor College of Medicine, Houston, TX, USA

$\begin{array}{ll}\begin{array}{l}\text { Abbreviations } \\ \text { CDC }\end{array} & \begin{array}{l}\text { Centers for Disease Control } \\ \text { and Prevention }\end{array} \\ \text { CI } & \begin{array}{l}\text { Confidence interval } \\ \text { COVID-19 }\end{array} \\ \text { Coronavirus disease 2019 } \\ \text { COVID-19-Associated } \\ & \begin{array}{l}\text { Hospitalization Surveillance } \\ \text { Network }\end{array} \\ \text { MIS-C } & \begin{array}{l}\text { Multisystem inflammatory } \\ \text { syndrome in children }\end{array} \\ \text { NH } & \text { Non-Hispanic } \\ \text { OR } & \text { Odds ratio }\end{array}$

Introduction

As of January 19, 2021, more than 23M cases of COVID-19 have been confirmed in the USA [1]. A recent report from the American Academy of Pediatrics and the Children's Hospital 
Association estimates nearly $2.5 \mathrm{M}$ total COVID-19 cases in US children [2]. Previous studies have shown that age, gender, race/ethnicity, and underlying medical conditions are independent risk factors for poor outcome in COVID-19 [3-6]. Understanding the role these factors play in severe acute respiratory syndrome coronavirus 2 (SARS-CoV-2) may inform clinicians, researchers, and governing agencies which children are at highest risk for severe COVID-19. Thus, our goal was to quantify the relationship between demographic factors and US pediatric COVID-19 hospitalization and death.

\section{Methods}

The Centers for Disease Control and Prevention COVID-19associated hospitalization surveillance network (CDC COVID-NET) is a population-based system that captures laboratory-confirmed COVID-19 cases in over 250 US acute-care hospitals [7]. $\mathrm{s}$-. The CDC COVID-NET is comprised of demographic variables (e.g., gender, age group, race and ethnicity, medical conditions) and date of positive SARSCoV-2 test, as well as outcomes, including hospitalization and mortality. Evidence of COVID-19 cases were evaluated for a postive detection of SARS-CoV-2 via nasopharyngeal/throat swabs or serologic testing. The database stratifies the variables as follows:

- Age group: stratified to 0-9 years or 10-19 years

- Gender: male or female

- Race and ethnicity: White, Non-Hispanic (NH); Black, NH; Hispanic/Latino; Asian, NH; Multiple/other, NH, Hawaiian/Pacific Islander, NH; Alaskan/American Indian, $\mathrm{NH}$

- Medical condition: yes or no

- Hospitalization: yes or no

- Death: yes or no

Our primary outcomes were hospitalization and in-hospital mortality. The data from the CDC COVID-NET was downloaded on August 17, 2020, and captured pediatric COVID-19 rates in the USA between March 2, 2020, and July 16, 2020. Although the database included a total of 229,052 children, we only included children that had complete information (e.g., no missing data). We examined the association of age, gender, race and ethnicity, and medical condition on hospitalization, followed by in-hospital mortality. The following underlying illnesses yielded a "yes" answer on the "medical condition" field: asthma, autoimmune disease, cardiovascular disease, chronic lung disease, gastrointestinal/ liver disease, hypertension, immune suppression, metabolic disease, neurologic disease, obesity, pregnancy, renal disease, or other disease.
All demographic variables were included in the multivariable logistic regression model. Odds ratios (OR) with $95 \%$ confidence intervals $(\mathrm{CI})$ were calculated. A $p$ value $<5 \%$ was considered statistically significant. Analyses were performed in STATA (version 13, College Station, TX). Since the data is publicly available and reported in a de-identified fashion, ethical approval to analyze the data was not warranted by local authorities.

\section{Results}

\section{Hospitalization}

A total of 27,045 US children with COVID-19 were included in this report. The majority $(n=18,924 ; 70.0 \%)$ of children were between the ages of 10 and 19 years with a similar gender distribution (please refer to Table 1). Hispanic/ Latino, White, non-Hispanic, and Black, non-Hispanic totaled $90.3 \%$ of the population. Thirty-nine percent $(n=10,438)$ of the children had an underlying medical condition.

Of the 27,045 children, 1,274 (4.7\%) required hospitalization. Multivariate analysis demonstrated that age, race/ethnicity, and medical conditions were significant features for hospitalization. Specifically, COVID-19-positive children $<10$ years of age [OR 1.5 (95\% CI 1.3, 1.7)] who were Black or of mixed race/ethnicity, and with a medical condition [OR $3.6(95 \%$ CI 3.1, 4.0)] associated with a higher odd for hospitalization (see Table 2).

\section{Mortality}

Mortality data was available for 20,096 (74.3\%) individuals that were hospitalized (refer to Table 3). Death occurred in $39(0.19 \%)$ hospitalized children. Demographic differences observed between survivors and non-survivors included race and an underlying medical condition. Children who were black, non-Hispanic [OR 3.0 (95\% CI 1.3, 6.7)], and those with an underlying medical condition [OR 8.8 (95\% CI 3.7, 21.1)] had an increased odd for death. Please see Table 4 for more details.

\section{Discussion}

In a large US cohort of confirmed COVID-19 children, we found that hospitalization occurred $4.7 \%$ of the time with an in-hospital mortality rate of $0.19 \%$. Cases of COVID-19 were more frequently observed in children older than 10 years of age and those of Hispanic/Latino and White, non-Hispanic race/ethnicity. However, children more likely to be hospitalized or die were Black, non-Hispanic and children with an 
Table 1 Demographic characteristics of hospitalized US children with COVID-19

\begin{tabular}{|c|c|c|c|c|}
\hline Variable & Total $(n=27,045)$ & $\begin{array}{l}\text { Non- } \\
\text { hospitalized } \\
(n=25,771)\end{array}$ & $\begin{array}{l}\text { Hospitalized } \\
(n=1,274)\end{array}$ & $p$ value \\
\hline Age & & & & $<0.01$ \\
\hline $0-9$ years & 8,121 & $7,639(94.1 \%)$ & $482(5.9 \%)$ & \\
\hline $10-19$ years & 18,924 & $18,132(95.8 \%)$ & $792(4.2 \%)$ & \\
\hline Sex & & & & 0.99 \\
\hline Female & 13,959 & $13,299(95.3 \%)$ & $660(4.7 \%)$ & \\
\hline Male & 13,086 & $12,472(95.3 \%)$ & $614(4.7 \%)$ & \\
\hline Race/ethnicity & & & & $<0.01$ \\
\hline White, NH & 7,974 & $7,717(96.8 \%)$ & $257(3.2 \%)$ & \\
\hline Black, NH & 4,224 & $3,876(91.8 \%)$ & $348(8.2 \%)$ & \\
\hline Hispanic/Latino & 12,236 & $11,697(95.6 \%)$ & $539(4.4 \%)$ & \\
\hline Asian, NH & 972 & $936(96.3 \%)$ & $36(3.7 \%)$ & \\
\hline Multiple/other, NH & 980 & $894(91.2 \%)$ & $86(8.8 \%)$ & \\
\hline Hawaiian/Pacific Islander, $\mathrm{NH}$ & 478 & $471(98.5 \%)$ & $7(1.5 \%)$ & \\
\hline Alaskan/American Indian, $\mathrm{NH}$ & 181 & $180(99.4 \%)$ & $1(0.6 \%)$ & \\
\hline Comorbidity & & & & $<0.01$ \\
\hline No & 16,607 & $16,195(97.5 \%)$ & $412(2.5 \%)$ & \\
\hline Yes & 10,438 & $9,576(91.7 \%)$ & $862(8.3 \%)$ & \\
\hline
\end{tabular}

NH non-Hispanic

underlying health condition. Interestingly, medical condition was the strongest risk factor for a poor outcome.

Table 2 Multivariable logistic regression evaluating risk factors associated with US pediatric COVID-19 hospitalization $(n=27,045)$

\begin{tabular}{llll}
\hline Variable & Odds ratio & $95 \%$ CI & $p$ value \\
\hline Age & & & \\
$\quad 0-9$ years & 1.48 & $1.31-1.67$ & $<0.01$ \\
10-19 years & 1 (reference) & - & - \\
Sex & & & \\
Female & 1.03 & $0.92-1.16$ & 0.56 \\
Male & 1 (reference) & - & - \\
Race/ethnicity & & & \\
White, NH & 1 (reference) & - & - \\
Black, NH & 2.28 & $1.93-2.70$ & $<0.01$ \\
Hispanic/Latino & 1.38 & $1.19-1.61$ & $<0.01$ \\
Asian, NH & 1.11 & $0.78-1.61$ & 0.56 \\
Multiple/other, NH & 2.95 & $2.28-3.82$ & $<0.01$ \\
Hawaiian/Pacific Islander, NH & 0.25 & $0.12-0.54$ & $<0.01$ \\
Alaskan/American Indian, NH & 0.20 & $0.03-1.42$ & 0.11 \\
Comorbidity & & & \\
No & 1 (reference) & - & - \\
Yes & 3.55 & $3.14-4.01$ & $<0.01$ \\
\hline
\end{tabular}

$\mathrm{CI}$ confidence interval, $\mathrm{NH}$ non-Hispanic
Our data showed that Black, non-Hispanic and Hispanic children were 2.5 times more likely than White children to be hospitalized and 5 times more likely to die after infection with SARS-CoV-2. Several reasons exist for this continued pattern of disproportionate impact of COVID-19 in minorities. First, parents are among the greatest vector of the disease to children [6]. As such, parents who work in high "viral-contact" jobs are more likely to be minorities. For example, Williams et al. [8] described that many of the industries (e.g., gyms, hair salons, restaurants) that remained open during the pandemic are driven by workers who are predominantly minority. Second, poverty is more common among minority groups. A study by Adhikari and colleagues [9] concluded that counties with higher rates of poverty and those with more diverse populations had significantly higher infection and death rates compared to counties with a substantial White population. Next, lower socioeconomic status is intricately linked to larger household sizes, crowding, and therefore more cross-infection [10]. This emphasized the needed to untangle the differences in immunologic response to SARS-CoV-2 based on race/ethnicity [11].

A past medical history of an underlying condition was the strongest risk factor for poor outcome in US children with COVID-19. An earlier report in Morbidity and Mortality Weekly Report noted that Hispanic and non-Hispanic Black children had a higher prevalence of underlying conditions when compared to White children $(45.7 \%$ vs. $29.8 \%$ vs. $14.9 \%$, respectively) [5]. Similarly, our analysis of 27,045 pediatric cases of COVID-19 found that Black, non- 
Table 3 Demographic characteristics of COVID-19positive children with in-hospital death

\begin{tabular}{|c|c|c|c|c|}
\hline Variable & $\begin{array}{l}\text { Total }(n= \\
20,096)\end{array}$ & $\begin{array}{l}\text { Survivors }(n= \\
20,057)\end{array}$ & $\begin{array}{l}\text { Non-survivor }(n= \\
39)\end{array}$ & $\begin{array}{l}p \\
\text { value }\end{array}$ \\
\hline Age & & & & 0.69 \\
\hline $0-9$ years & 6,104 & $6,091(99.8 \%)$ & $13(0.2 \%)$ & \\
\hline $10-19$ years & 13,992 & $13,966(99.8 \%)$ & $26(0.2 \%)$ & \\
\hline Sex & & & & 0.95 \\
\hline Female & 10,415 & $10,395(99.8 \%)$ & $20(0.2 \%)$ & \\
\hline Male & 9,681 & $9,662(99.8 \%)$ & $19(0.2 \%)$ & \\
\hline Race/ethnicity & & & & $<0.01$ \\
\hline White, NH & 6,231 & $6,222(99.9 \%)$ & $9(0.1 \%)$ & \\
\hline Black, NH & 3,182 & $3,166(99.5 \%)$ & $16(0.5 \%)$ & \\
\hline Hispanic/Latino & 8976 & $8,965(99.9 \%)$ & $11(0.1 \%)$ & \\
\hline Asian, NH & 645 & $645(100 \%)$ & $0(0 \%)$ & \\
\hline Multiple/other, $\mathrm{NH}$ & 677 & $674(99.6 \%)$ & $3(0.4 \%)$ & \\
\hline $\begin{array}{l}\text { Hawaiian/Pacific Islander, } \\
\mathrm{NH}\end{array}$ & 273 & $273(100 \%)$ & $0(0 \%)$ & \\
\hline $\begin{array}{l}\text { Alaskan/American Indian, } \\
\text { NH }\end{array}$ & 112 & $112(100 \%)$ & $0(0 \%)$ & \\
\hline Comorbidity & & & & $<0.01$ \\
\hline No & 12,581 & $12,575(99.95 \%)$ & $6(0.05 \%)$ & \\
\hline Yes & 7,515 & $7,482(99.6 \%)$ & $33(0.4 \%)$ & \\
\hline
\end{tabular}

NH non-Hispanic

Hispanic children had a higher proportion of comorbidities when compared to White children (49.6\% vs. $37.3 \%)$. Our findings that comorbidity and minority populations are at

Table 4 Multivariable logistic regression evaluating risk factors associated with pediatric COVID-19 in-hospital death $(n=20,096)$

\begin{tabular}{llll}
\hline Variable & Odds ratio & $95 \% \mathrm{CI}$ & $p$ value \\
\hline Age & & & \\
$\quad 0-9$ years & 1.24 & $0.63-2.43$ & 0.53 \\
$\quad 10-19$ years & 1 (reference) & - & - \\
Sex & & & \\
Female & 0.98 & $0.52-1.85$ & 0.96 \\
Male & 1 (reference) & - & - \\
Race/ethnicity & & & \\
White, NH & 1 (reference) & - & - \\
Black, NH & 2.96 & $1.30-6.73$ & 0.01 \\
Hispanic/Latino & 0.88 & $0.36-2.13$ & 0.78 \\
Asian, NH & 1 & - & - \\
Multiple/other, NH & 3.33 & $0.90-12.37$ & 0.07 \\
Hawaiian/Pacific Islander, NH & 1 & - & - \\
Alaskan/American Indian, NH & 1 & - & - \\
Comorbidity & & & \\
No & 1 (reference) & - & - \\
Yes & 8.82 & $3.68-21.1$ & $<0.01$ \\
\hline
\end{tabular}

increased risk for COVID-19 death is reiterated in a study by Ahmed et al. [12]. Another recent meta-analysis examined the association of pediatric comorbidities with COVID-19 infection. In 42 studies, encompassing 275,661 children, Tsankov et al. summarized that children with comorbidities had a relative risk ratio of 1.79 for severe COVID-19 infection and 2.81 for COVID-19-related mortality.

There are limitations to our study. First, although the data is derived from 14 states, it only represents $10 \%$ of the US population. Second, missing data was common in the database which decreased our overall sample size from 229,052 children to 27,045 pediatric cases. In particular, medical conditions had more than $50 \%$ of the data unknown or missing. Despite finding that a history of medical conditions impacts the trajectory of childhood COVID-19, the database is not granular in providing the specific conditions for each patient.

To our knowledge, this is the largest pediatric evaluation investigating demographic information as risk factors of COVID-19 hospitalization and death. Implications from our study are threefold: (i) gender may not play a significant role in childhood COVID-19 severity, (ii) race and ethnicity, and underlying medical conditions, are vital risk factors for COVID-19 hospitalization or death, and (iii) younger age increases hospitalization risk, but not death. Future studies should focus on unraveling the mechanisms underpinning poor COVID-19 outcomes in Black, non-Hispanic children, as well as those with medical conditions.

$\mathrm{CI}$ confidence interval, $\mathrm{NH}$ non-Hispanic 
Authors' Contributions Drs. Alvaro and Axel Moreira conceptualized and designed the study, drafted sections of the initial manuscript, carried out the analyses, and supervised the project.

Dr. Ahmed assisted with conceptualization, wrote sections of the initial manuscript, and critically reviewed and revised the manuscript.

Drs. Chorath and Rajasekaran and Ms. Burmeister assisted with conceptualization and critically reviewed and revised the manuscript.

All authors approved the final manuscript as submitted and agree to be accountable for all aspects of the work.

Funding Parker B. Francis fellowship grant. The Francis Foundation had no role in the design or conduct of this study.

Data availability Publicly available data.

\section{Declarations}

Ethics approval and consent to participate Not applicable.

Consent for publication Not applicable.

Conflict of interest The authors declare no conflict of interest.

Code availability Not applicable.

\section{References}

1. COVID Data Tracker. Centers for Disease Control and Prevention. Covid.cdc.gov/covid-data-tracker/\#cases_totalcases. Accessed 19 Jan 2021

2. Children and COVID-19: State-Level Data Report. American Academy of Pediatrics. Services.aap.org/en/pages/2019-novelcoronavirus-covid-19-infections/children-and-covid-19-state-leveldata-report. Accessed 19 Jan 2021

3. Götzinger F, Santiago-García B, Noguera-Julián A, Lanaspa M, Lancella L, Calò Carducci FI, Gabrovska N, Velizarova S, Prunk P, Osterman V, Krivec U, Lo Vecchio A, Shingadia D, SorianoArandes A, Melendo S, Lanari M, Pierantoni L, Wagner N, L'Huillier AG, Heininger U, Ritz N, Bandi S, Krajcar N, Roglić S, Santos M, Christiaens C, Creuven M, Buonsenso D, Welch SB, Bogyi M, Brinkmann F, Tebruegge M, Pfefferle J, Zacharasiewicz A, Berger A, Berger R, Strenger V, Kohlfürst DS, Zschocke A, Bernar B, Simma B, Haberlandt E, Thir C, Biebl A, vanden Driessche K, Boiy T, van Brusselen D, Bael A, Debulpaep S, Schelstraete P, Pavic I, Nygaard U, Glenthoej JP, Heilmann Jensen L, Lind I, Tistsenko M, Uustalu Ü, Buchtala L, Thee S, Kobbe R, Rau C, Schwerk N, Barker M, Tsolia M, Eleftheriou I, Gavin P, Kozdoba O, Zsigmond B, Valentini P, Ivaškeviciene I, Ivaškevicius R, Vilc V, Schölvinck E, Rojahn A, Smyrnaios A, Klingenberg C, Carvalho I, Ribeiro A, Starshinova A, Solovic I, Falcón L, Neth O, Minguell L, Bustillo M, Gutiérrez-Sánchez AM, Guarch Ibáñez B, Ripoll F, Soto B, Kötz K, Zimmermann P, Schmid H, Zucol F, Niederer A, Buettcher M, Cetin BS, Bilogortseva O, Chechenyeva V, Demirjian A, Shackley F, McFetridge L, Speirs L, Doherty C, Jones L, McMaster P, Murray C, Child F, Beuvink Y, Makwana N, Whittaker E, Williams A, Fidler K, Bernatoniene J, Song R, Oliver Z, Riordan A (2020) COVID-19 in children and adolescents in Europe: a multinational, multicentre cohort study. Lancet Child Adolesc Health 4(9):653-661
4. Shekerdemian LS, Mahmood NR, Wolfe KK et al (2020) Characteristics and outcomes of children with coronavirus disease 2019 (COVID-19) infection admitted to us and canadian pediatric intensive care units [published online ahead of print, 2020 May 11]. JAMA Pediatr. https://doi.org/10.1001/jamapediatrics.2020.1948

5. Kim L, Whitaker M, O’Halloran A, Kambhampati A., Chai S.J., Reingold A., Armistead I., Kawasaki B., Meek J., Yousey-Hindes K., Anderson E.J., Openo K.P., Weigel A., Ryan P., Monroe M.L., Fox K., Kim S., Lynfield R., Bye E., Shrum Davis S., Smelser C., Barney G., Spina N.L., Bennett N.M., Felsen C.B., Billing L.M., Shiltz J., Sutton M., West N., Talbot H.K., Schaffner W., Risk I., Price A., Brammer L., Fry A.M., Hall A.J., Langley G.E., Garg S., COVID-NET Surveillance Team, COVID-NET Surveillance Team, Coates A., Daily Kirley P., Libby T., Roland J., Alden N., Herlihy R., McLafferty S., Clogher P., Kayalioglu H., Maslar A., Misiorski A., Niccolai L., Olson D., Parisi C., Fawcett E., Gretzinger S., Lengacher K., Williams J., Blythe D., Brooks A., Park R., Wilson M., Como-Sabetti K., Danila R., Cline C., Angeles K., Eisenberg N., Flores K., Habrun C., Hancock E., Khanlian S., Novi M., Phipps E., Salazar-Sanchez Y., Dufort E., Muse A., Bushey S., Gaitan M., Kurtz R.A., Owusu-Dommey A., Snyder L., Michaelis K., Seeley K., Markus T., Chatelain R., George A., Hill M., McCullough L., Spencer M., Swain A., McCaffrey K., Holstein R., Meador S., Wortham J. Hospitalization rates and characteristics of children aged $<18$ years hospitalized with laboratory-confirmed COVID-19 - COVIDNET, 14 states, March 1-July 25, 2020. MMWR Morb Mortal Wkly Rep 2020;69:1081-1088

6. Hoang A, Chorath K, Moreira A et al (2020) COVID-19 in 7780 pediatric patients: a systematic review. EClinicalMedicine 24: 100433

7. Coronavirus disease 2019-associated hospitalization surveillance network (COVID-NET). Centers for Disease Control and Prevention. Cdc.gov/coronavirus/2019-ncov/covid-datacovid-net/ purpose-methods.html. Last accessed on 9.17.2020

8. Williams JC, Anderson N, Holloway T, Samford E 3rd, Eugene J, Isom J. Reopening the United States: Black and Hispanic workers are essential and expendable again [published correction appears in Am J Public Health. 2021 Jan;111(1):e2]. Am J Public Health 2020;110(10):1506-1508. https://doi.org/10.2105/AJPH.2020. 305879

9. Adhikari S, Pantaleo NP, Feldman JM, Ogedegbe O, Thorpe L, Troxel AB (2020) Assessment of community-level disparities in coronavirus disease 2019 (COVID-19) infections and deaths in large US metropolitan areas. JAMA Netw Open 3(7):e2016938. https://doi.org/10.1001/jamanetworkopen.2020.16938

10. Sze S, Pan D, Nevill CR, Gray LJ, Martin CA, Nazareth J, Minhas JS, Divall P, Khunti K, Abrams KR, Nellums LB, Pareek M (2020) Ethnicity and clinical outcomes in COVID-19: a systematic review and meta-analysis. EClinicalMedicine. 29:100630. https://doi.org/ 10.1016/j.eclinm.2020.100630

11. Tal Y, Adini A, Eran A, Adini I (2020) Racial disparity in Covid-19 mortality rates - a plausible explanation. Clin Immunol 217: 108481. https://doi.org/10.1016/j.clim.2020.108481

12. Ahmed M, Advani S, Moreira A, Zoretic S, Martinez J, Chorath K, Acosta S, Naqvi R, Burmeister-Morton F, Burmeister F, Tarriela A, Petershack M, Evans M, Hoang A, Rajasekaran K, Ahuja S, Moreira A (2020) Multisystem inflammatory syndrome in children: a systematic review. EClinicalMedicine. 26:100527. https://doi. org/10.1016/j.eclinm.2020.100527

Publisher's note Springer Nature remains neutral with regard to jurisdictional claims in published maps and institutional affiliations. 